\title{
Borrando los límites: Deconstrucción interdisciplinar del concepto de espacio público
} Blurring limits: Interdisciplinary deconstruction on the concept of Public Space

Edwin Aguirre Ramírez, Alejandro Peimbert Duarte

\section{Filiación}

Universidad Autónoma de Ciudad Juárez, México, Universidad Autónoma de Baja California, México

E mail: dredwinagra@gmail.com, alejandro.peimbert@uabc.edu.mx

Primera versión recibida en: 19 de marzo, 2015

Última versión recibida en: 17 de junio, 2016

\section{Resumen}

Ante el surgimiento de puntos de encuentro entre diversas disciplinas que hablan de la ciudad o de lo urbano, el texto procura una deconstrucción del concepto de espacio público. Se expone una discusión entre autores de ámbitos tales como la antropología, la sociología, la geografía, el urbanismo y la arquitectura. La disolución de los límites entre disciplinas y las diversas formas de abordaje teórico y metodológico de las mismas se hacen evidentes al abundar en una relación clave: la del sujeto y el espacio habitable. En el artículo se mencionan ciertas nociones asociadas al concepto de espacio público: territorio, lugar, paisaje; inevitablemente estas emergen de las disciplinas que le dan sentido, pero la deconstrucción manifiesta que ahora, por ejemplo, la antropología precisa del aporte de visiones macro, mientras que el urbanismo no puede obviar la preponderancia del sujeto para el estudio, la planificación o el diseño de los espacios abiertos. Esto, visto como un desafío para cada una de las disciplinas implicadas, acarrea la posibilidad de que aparezcan nuevas preguntas de investigación y pone en la mesa el modo en que el concepto se ha transformado, permaneciendo vigente. Esto, posiblemente cuestione aquellas voces que anuncian la muerte del espacio público.

\section{Palabras clave}

Espacio público; espacio urbano; lugar; paisaje; territorio.

\begin{abstract}
With the emergence of nodes between different disciplines that speak of the city or the urban, the text seeks to deconstruct the concept of public space. A discussion between authors of fields such as anthropology, sociology, geography, urban planning and architecture is presented. The dissolution of boundaries between disciplines and the various forms of theoretical and methodological approach of these are evident when one elaborates a key relationship: the subject and the living space. In the article, certain notions associated with the concept of public space are mentioned: territory, place and landscape; inevitably emerge from these disciplines that give meaning, but deconstruction now states that anthropology -for example- precises contribution of macro visions, while urbanism cannot ignore the preponderance of subject for studying, planning or design of open spaces. This, seen as a challenge to each of the disciplines involved, carries the possibility of the emergence of new research questions and put on the table how the concept has changed, remaining in force. Also, this possibly questioning those voices that announce the death of public space.
\end{abstract}

\section{Keywords}

Public space; urban space; place; landscape; territory. 


\section{Sumario}

Introducción

1 Sociología y antropología de lo urbano: el sentido de lo relacional del espacio público

2 Geografía, urbanismo y arquitectura: líneas tangenciales con el espacio público

3 Reflexiones finales

\section{Referencias}

\section{Introducción}

El objetivo de este texto es deconstruir una visión integral del concepto del espacio público por medio de un diálogo/discusión entre autores, que procura borrar los límites entre disciplinas y las diversas formas de abordaje teórico metodológico de las mismas. Denotamos que el concepto de deconstrucción aquí empleado hace una referencia libre a los planteamientos iniciales de Derrida (1989) para establecer la diferencia, unas veces más amplia que otras, que posee el concepto del espacio público a partir de la construcción histórica y multidisciplinar del mismo. Es así que se analizan y se ponen en consideración variadas concepciones del espacio público, lo que conlleva a establecer múltiples diferencias, pero también muchos puntos en común de dichas conceptualizaciones. Para efectos de acotación disciplinar se han considerado la sociología urbana, la geografía, el urbanismo, la arquitectura y la antropología, puesto que son áreas del conocimiento que utilizan diversos conceptos relacionados con el espacio, el lugar, el paisaje, la región y el territorio, por tanto, los temas comunes entre ellas adquieren relevancia para la construcción del concepto.

La propuesta aquí presentada surge de la sumatoria de intereses individuales relacionados con los proyectos de tesis doctoral de dos arquitectos que han visto en el tema de lo urbano y el espacio público, problemáticas que necesitan ser resueltas desde lo conceptual hasta lo empírico. La formación doctoral en ciencias sociales y en estudios socioculturales de los investigadores, les ha permitido dar una mirada distinta al concepto del espacio público, que complementa la visión tradicional que existe desde la concepción urbano arquitectónica, a partir de lo cual se evidencia que un acercamiento a la solución de dicha problemática solo se puede dar desde una postura interdisciplinaria.

El espacio público se presenta como un concepto propicio para estudiar la ciudad - simultánea y articuladamente- situado en las diversas trincheras disciplinares antes mencionadas. Las diferencias y similitudes entre cada uno de los discursos emitidos desde estas disciplinas son justamente los factores que dan terreno a las tensiones y conciliaciones que motivan nuevos objetos de estudio y que contribuyen a elaborar nuevas preguntas de investigación, haciendo manifiesta la presencia del sujeto y sus diversas prácticas en los lugares donde viven. El sentido del habitar adquiere una dimensión o una escala más genérica cuando se saca del espacio exclusivo de la vivienda, en otras palabras, cuando se pone en un contexto colectivo, en el espacio urbano, en el espacio público. En este sentido, la comprensión de las formas en las que se habita la ciudad y, en especial las formas en las que se puede habitar lo público, son fundamentales para comprender la configuración actual del concepto en símismo.

A lo anterior debemos sumarle que el concepto del espacio público, hoy por hoy, no puede entenderse exclusivamente por medio de la objetivación, situación que ha sido usual en la mirada urbano arquitectónica. Es necesario que la comprensión del concepto se realice a partir de la relación que existe entre él con los sujetos que lo habitan, en otras palabras, comprender la relación entre espacio público y usuario implica un reconocimiento del valor subjetivo del concepto mismo, que lo hace mucho más complejo y, a la vez, que permite que la mirada interdisciplinar sea fundamental para la consolidación de su importancia. Las relaciones de los 
sujetos con y en el espacio son vitales para articular la visión interdisciplinar del espacio público y, hacer cada vez más sólido el argumento de que este elemento de la estructura urbana (entendido desde su realidad física espacial) es imprescindible para la consolidación y desarrollo sustentable de nuestras ciudades.

El documento que se presenta a continuación está estructurado de la siguiente manera: la primera parte nos permite ver la relación intrínseca de dos disciplinas como la sociología urbana y la antropología urbana, mismas que tienen como centro de su interés lo que sucede con la sociedad y con los sujetos en los contextos urbanos. Actualmente, ambas áreas del conocimiento buscan develar la importancia del contexto físico en las relaciones sociales y el desarrollo de los individuos, por tanto, es fundamental comprender las apuestas conceptuales que hacen respecto de la configuración del espacio público. La segunda parte del documento presenta las disciplinas de la geografía, el urbanismo y la arquitectura, mismas que tienen una visión del concepto de espacio más específica, pero que difieren en las escalas de interpretación, situación que a la vez ha generado el interés por dinamizar el concepto del espacio público, ya no como elemento aislado, sino como parte integral de un sistema territorial que puede manifestarse de distintas formas.

En la tercera parte se presentan las reflexiones finales de este diálogo/discusión entre autores y disciplinas, que deben ser entendidas como interpretaciones de la diferenciación/deconstrucción (Powell y Howell, 2004) del espacio público, formuladas desde la experiencia académica y profesional de los autores de este texto $y$, desde su interés por argüir la importancia de una conceptualización integral.

\section{Sociología y antropología de lo urbano: el sentido de lo relacional del espacio público}

Tanto la sociología urbana como la antropología urbana, se han convertido en disciplinas de referencia si se quieren entender los diversos fenómenos de carácter socioeconómico y cultural que se dan en la ciudad. Es importante mencionar que ambas perspectivas congregan estudios de y en la ciudad, situación que, aunque compleja, manifiesta la relevancia de estos temas de estudio y los elementos que los constituyen. La comprensión del concepto del espacio público y su papel como escenario de relaciones entre los elementos físicos de la ciudad y la población que habita en ella ha sido estudiada por medio de estas disciplinas desde diversas perspectivas. Si bien son múltiples los autores que han intentado configurar un pensamiento estructurado de los conceptos de espacio, espacio urbano y ciudad, resultan de gran importancia los planteamientos fundados en los postulados marxistas, en donde se relaciona la capacidad de producción del espacio, con las condiciones generales de la producción (en términos económicos) y la reproducción de la sociedad (Castells, 1976; Harvey, 1985; Lefebvre, 1991). Desde puntos de vista más específicos, estas disciplinas buscan, por un lado discernir las diferencias entre lo público y lo privado, desde perspectivas económicas, jurídicas y sociológicas (Borja, 2003; Duhua y Giglia, 2008; Madanipour, 2003; Zukin, 1993); y por otro, reflejar la importancia del espacio público en la vida cotidiana de las comunidades y los individuos urbanos, situación que se representa por medio de imaginarios, la escenificación y espacialización de las relaciones humanas y el sentido de pertenencia, entre otros (Aguilar, 2012; Delgado, 1999; Signorelli, 2012).

Para iniciar con la comprensión del sentido relacional de los espacios y los sujetos sociales, así como la relación de las disciplinas antes mencionadas, se debe hacer mención a los postulados de Lefebvre (1991), que manifiestan que la voluntad del individuo y de la sociedad es la que logra construir el espacio. La acción de los grupos sociales es lo que facilita que se dé la producción de este, de manera tal que, desde su origen, el espacio contiene un significado 
particular dado por aquellos quienes lo han construido. El objetivo que tiene Lefebvre es develar que las prácticas sociales, son también prácticas espaciales. Así pues, considerar el espacio como un elemento producido socialmente, permite vislumbrar una dialéctica entre sujetos, pero al mismo tiempo, entre ellos y el contexto en donde se encuentran ubicados (el espacio y el tiempo), dándose así una práctica relacional, social y espacial, que está en un constante fluir (Lefebvre, 1991, p. 11).

A partir de lo anterior, se debe entender que la práctica espacial, los espacios de representación y los espacios figurativos (que configuran la triada conceptual principal para entender la producción social del espacio), se dan en un modo de producción definido (el capitalista) y en un momento histórico específico. La relación entre lo percibido, lo concebido y lo vivido nunca puede entenderse como algo estable (Lefebvre, 1911, p. 46), dado que la acción de los sujetos, sus diferencias cognitivas, su cultura y su capacidad de agencia (entre muchos otros factores), son los elementos que dinamizarán los procesos de producción social del espacio, que puede entenderse también como el sentido de lo relacional en el espacio público.

Desde otra perspectiva, la organización de los actores sociales, de los individuos y los grupos, pertenecientes a clases diferenciadas y ligadas a un mismo espacio, en la relación que establecen entre ellas y con el espacio, dan cuenta de que la constitución misma de dichas relaciones es una forma de producción social de un contexto integral (espacial, temporal, social). En este sentido, Castells (1976) considera que la sociedad puede ser vista como una expresión de la articulación de diversos intereses, en donde los agentes sociales estarán siempre motivados por mantener múltiples relaciones: en otras palabras, esta acción de los individuos puede ser entendida como una forma de participación en los procesos de producción del espacio social y del espacio público. Al decir esto, puede asumirse que para este autor la relación entre espacio e individuos es intrínseca (Castells, 1976, p. 141), dado que ambos pueden ser vistos como elementos materiales relacionados entre sí. La acción del individuo y de los grupos sociales puede ser entendida como una articulación entre diversos intereses, en donde el espacio siempre será parte constitutiva de lo relacional. En otras palabras, la interacción social se da entre los individuos y entre ellos con el espacio. Es así que la acción de los sujetos siempre incidirá en la forma y en la funcionalidad de los espacios y, a la vez, estos pasarán a ser elementos que condicionan la forma de acción de los sujetos sociales.

Si bien estas relaciones planteadas hasta ahora parecieran ser muy generales, se constituyen como una forma de entender el espacio público y sus símiles y su inexorable relación con la sociedad de manera genérica. A pesar de esto, algunos postulados ayudan a definir escalas más acotadas de interpretación, que permiten acercarnos más a los individuos y el sentido intersubjetivo de relación con el espacio. Es así como Harvey afirma que "el espacio social está compuesto por un conjunto de sentimientos, imágenes y reacciones con respecto al simbolismo espacial que rodea al individuo. Cada persona, según parece, vive su propia red de relaciones espaciales personalmente construidas" (Harvey, 1985, p. 28). En este sentido, se puede decir que no solo se habla de una producción social del espacio, sino de una producción social de relaciones, de redes, las cuales configuran siempre nuevas formas de espacios. A la vez, se debe entender que las relaciones funcionales entre los procesos sociales y el espacio pueden ser vistas de forma colectiva o de manera independiente y, al entender que la acción de los individuos es dinámica, la configuración y formas de producción del espacio pueden ser objeto de modificaciones permanentes.

En una escala más precisa, la de la ciudad y lo urbano, se hace necesario establecer los elementos de la configuración dicotómica del espacio, se debe definir lo que es espacio privado y lo que es espacio público. La importancia de la definición de estos dos elementos radica en que el espectro de los conceptos de lo privado y de lo público es muy amplio y, no 
necesariamente se refieren a categorías espaciales, sino también a los ámbitos de la política y la filosofía, por mencionar algunos. Es así que las esferas de lo privado y de lo público han sido estipuladas históricamente por la sociedad y esta división ha sido un principio de organización de la vida urbana, en donde se ha dado forma también, a la diferencia entre el espacio de la ciudad y la vida social de los ciudadanos: "La relación entre lo público y lo privado ha superpuesto dimensiones económicas, sociales, culturales y políticas, y tiene una visión física claramente visible, tal vez mayor que ninguna otra forma de estructuración de la ciudad" (Madanipour, 2003, p. 3). La reflexión de este autor revela, a diferentes escalas, la importancia estructural de los conceptos de lo público y lo privado, a la vez que pone de manifiesto que la vida social y la vida urbana están moldeadas por estos elementos. Lo público y lo privado determinan formas de la vida cotidiana y maneras de relaciones entre los individuos y la sociedad.

Es común entender esta relación de forma dicotómica, o sea, como si estos conceptos estuvieran en una discusión constante e indefinida, en una disputa permanente. A pesar de que las realidades urbanas lo expresan así muchas veces, en la visión de Madanipour se intenta lograr una relación dialógica, que permite ver la correspondencia intrínseca entre los dos elementos y la complementariedad que existe entre ellos. Un ejemplo de lo anterior, visto en términos escalares o de tipología espacial, es la consideración que hace el autor acerca del espacio personal, el cual puede entenderse como una extensión del cuerpo de las personas, una cápsula o burbuja alrededor de nosotros mismos y de los otros:

El espacio personal es un espacio subjetivo alrededor de los individuos, no es visible ni real. Es al mismo tiempo objetivo, en el sentido de que los individuos y los otros parecen estar de acuerdo en que lo observan, aunque pueden estar en desacuerdo sobre los métodos de esta observación y el tamaño que posee ese espacio personal (...) Es denominado territorio portátil. Es el espacio en el cual los individuos realizan sus actos sociales, en donde se sienten seguros y en control de sus cuerpos (Madanipour, 2003, p. 24).

No se puede simplificar la concepción de lo público únicamente como un opuesto a lo privado y, lo planteado anteriormente es demostración del contacto permanente entre los umbrales de uno y otro tipo de espacio. Si se considera que lo privado corresponde al espacio del yo, a un espacio de lo subjetivo, del cuerpo, de la vivienda, lo exterior a esto es el espacio público, pero el límite entre uno y otro puede ser muy delgado, incluso en muchas ocasiones puede desdibujarse. Madanipour no desconoce que en nuestro tiempo se ha dado una decadencia, o mejor, una transformación constante de los espacios públicos, los cuales se han convertido en lugares para moverse, de tránsito, y no en lugares para estar y habitar, como se consideró en algunos contextos, lo que a la vez ha generado una disminución considerable en la capacidad de socialización de los habitantes de la ciudad. Hoy, el espacio público puede contener múltiples elementos y, en algunos casos, puede ser considerado como el intersticio que queda entre los espacios privados.

Desde otra perspectiva, Jordi Borja (2003) presenta una radiografía muy completa acerca de lo que significa la ciudad y, en particular, del papel que juega el espacio público en la construcción de ciudad y ciudadanía. De alguna manera, en esta concepción tiene más relevancia la visión del espacio desde la perspectiva de la sociedad y sus instituciones, mismas que fungen como ordenadoras de lo que concierne al espacio urbano. Es interesante ver que, a la hora de clarificar el significado del espacio público, este autor considera importante ver este concepto desde su raíz legal, en donde se expresa de nuevo la dualidad privado-público: “El espacio público como concepto jurídico es un espacio sometido a una regulación específica por parte de la administración pública, propietaria o que posee la facultad de dominio sobre el suelo y que 
garantiza la accesibilidad a todos y fija las condiciones de utilización y de instalación de actividades" (Borja, 2003, p. 122). Es claro que, para Borja, si bien la estructura de la diferencia entre lo privado y lo público hace parte de una expresión de lo legal, de los derechos y deberes de los individuos para con la ciudad, no se puede desconocer que sugiere otras dimensiones de igual importancia en su conceptualización sobre lo público. El papel de las instituciones se convierte en un factor fundamental para comprender la separación conceptual y real entre lo público y lo privado, generando estructuras de comportamiento, de valor y de uso en cada tipo de espacio, propendiendo por dejar límites claros y establecidos. El espacio público en esta concepción evoca la idea clásica que dio origen al mismo, que considera este elemento como la esencia misma de la ciudad, que pertenece a todos y es característica fundamental de la democracia.

En este mismo orden se puede establecer que el espacio público posee características que dependen, en esencia, tanto de los sujetos y de la sociedad, como de las instituciones, constituyendo su estructura a partir de elementos que están más allá de lo físico y de lo espacial. Podemos considerar la normatividad como base fundamental de esas características, para ello, debemos entenderla como estructura que guía el comportamiento de sujetos y grupos sociales en la vida cotidiana y, en particular en el espacio urbano. A pesar de esto, el comportamiento en sí mismo, entendido como acción individual o colectiva, puede darse dentro de esa estructura normada, pero de igual forma, puede estar por fuera de ella. El peso de estos dos elementos, normas y comportamientos (o estructura y acción, si se quiere), define la relación intrínseca que existe entre espacio y sociedad-sujeto. Respecto de esto, Emilio Duhau y Angela Giglia consideran que: “El espacio público, aunque nos guste pensarlo como un espacio abierto y libre, en efecto está marcado en su ausencia no solo por la cuestión de la convivencia de sujetos heterogéneos, sino en particular por la cuestión de las normas comunes y de la común aceptación de las normas, sean estas explícitas o implícitas, formales o informales, rígidas o flexibles" (Duhahu y Giglia, 2008, p. 51). Aquí, la dicotomía entre lo público y lo privado se hace más evidente, puesto que se pone de manifiesto que las normas que rigen el funcionamiento del espacio público, suscitan fenómenos que pueden ir en contra de la estructura misma de las cualidades y valores de este espacio. Así pues, aparecen en escena dinámicas privatizadoras, de segregación, de deterioro y de abandono del espacio urbano, que a la vez son una expresión de las formas en que los ciudadanos se relacionan con su contexto habitable. Para estos autores, lo anterior puede entenderse como una forma de disociación entre los espacios públicos y las prácticas urbanas y según ellos, la evolución de esta problemática se ha dado por medio de dos lógicas: la privatización y la especialización.

Los elementos normativos y las estructuras, tanto como los comportamientos de los sujetos y la sociedad en lo relativo al espacio urbano, se dan muchas veces a partir de las cuestiones ligadas con el poder económico. Para profundizar en esto nos permitimos recuperar lo que aporta la socióloga estadounidense Sharon Zukin (1993), derivado de la distinción entre los conceptos de lugar y paisaje. La autora argumenta que el lugar, entendido como una localización geográfica en el territorio, puede ser una concentración de personas y de actividades económicas, lo que configura una sociedad local reproducida de manera espacial por su economía y su demografía y, que de manera inmediata evoca una imagen particular del contexto que configura. Por otro lado, afirma que el concepto de paisaje no solamente denota el significado usual correspondiente a un "entorno físico", sino que se refiere a un conjunto de prácticas sociales y materiales, al mismo tiempo que su representación simbólica: “Paisaje representa la construcción espacial de clase social, género y relaciones de raza impuestas por instituciones con poder. (...) Esto connota el panorama que percibimos: el paisaje del poderío catedrales, fábricas y rascacielos- y el paisaje del subordinado -capillas, suburbios y vivienda marginal" (Zukin, 1993, p. 16). A partir de lo anterior podemos asegurar que, cuando un 
espacio público es comprendido como lugar, este podrá evocar los límites visibles y las prácticas que -estas últimas, más o menos ocultas- también lo constituyen; mientras que, cuando el espacio público es comprendido como paisaje, lo distinguirán no solamente las actividades, sino que sus demarcaciones asignadas o impuestas, desde una posición hegemónica, se manifestarán en materia y esta prevalecerá en la medida en que las tensiones con su opuesto lo permitan. El producto de estas diferencias estará edificando ese entorno que Zukin denomina "paisajes del poder".

Desde un punto argumental centrado en el sujeto (y ya no solo desde los grupos sociales), el abordaje desde la antropología urbana hace énfasis en las prácticas espaciales de estos para apropiarse y dar significación al espacio público. En este sentido, comprender las relaciones entre sujetos y de ellos con el espacio, son indispensables. Es pertinente aquí el reemplazo del concepto de espacio por la noción de lugar, el primero, entendido siempre como un elemento físico, aislado o no, de quien puede utilizarlo y; el segundo, por su parte, entendido siempre como un elemento que promueve un sentido de pertenencia, así como prácticas relativas a la vida cotidiana en el espacio urbano y, por supuesto, promotor de características identitarias en los sujetos urbanos.

Manuel Delgado (1999) se ha ocupado de revisar el concepto de espacio público, propiciando que este se torne en un objeto de estudio factible para el análisis antropológico. Delgado se encarga de definir las implicaciones epistemológicas del espacio público, entendiéndolo como objeto a ser observado, descrito y analizado. Pero, inicialmente, menciona que el espacio público tiende a constituirse en escenario de un tipo insólito de estructuración social, organizada en torno al anonimato y la desatención mutua o bien a partir de relaciones efímeras basadas en la apariencia, la percepción inmediata y relaciones altamente codificadas y en gran medida fundadas en el simulacro y el disimulo (Delgado, 1999, p. 12). Los participantes de los fragmentos de ciudad, según Delgado, viven "relaciones transitorias y que se construyen a partir de pautas dramatúrgicas o comediográficas - es decir basadas en una cierta teatralidad-, que resultan al mismo tiempo ritualizadas e impredecibles, protocolarias y espontáneas" (Delgado, 1999, p. 13). Estos participantes forman una sociedad dispersa que se va conformando al mismo tiempo que se desvanece. Explica Delgado que el espacio público se trata del ámbito por antonomasia del juego, de la alteridad generalizada, en donde los practicantes experimentan una suerte de placer al complejizar las reglas de un contrato social cotidiano y renovado de manera intermitente, dicho contrato es conocido como urbanidad.

El espacio, tanto desde la visión de la sociología urbana como de la antropología urbana, no es un elemento dado y estático, por el contrario, es producido constantemente por medio de la acción individual y colectiva. El sentido y el significado que generan la apropiación del espacio, factores que lo transforman en lugar - desde la mirada antropológica-, son esenciales para comprender la complejidad del espacio urbano en sí mismo, como también, aquellos elementos que lo componen. Aguilar considera el lenguaje como uno de los elementos que transforma constantemente el espacio: “Es factible pensar en el lugar no como algo ya dado, sino intervenido por la acción humana, en la medida en que la valoración del lugar se vuelve parte integral del mismo (...) los límites del lugar no dependen necesariamente de un aspecto físico o de delimitaciones materiales, sino principalmente de demarcaciones cognitivas expresadas a través del lenguaje" (Aguilar, 2012, pp. 121-122). Esta reflexión manifiesta, en otras palabras, el sentido de lo relacional, dado a partir de la implicación del lenguaje. Si entendemos esto como parte estructural de las relaciones sociales, entonces podemos suponer la acción en el espacio público, como un acto del lenguaje en sí mismo, como forma de comunicarnos con los otros habitantes de la ciudad. En este mismo orden de ideas, se puede establecer que hay multiplicidad de espacios públicos o de lugares (para mantener el sentido antropológico), como habitantes existen. La puesta en escena de las individualidades en el espacio urbano son una 
extrapolación de las relaciones sociales, mismas que configuran múltiples sentidos y significados. Amalia Signorelli sostiene que el sentido de lo relacional coadyuva a definir las espacialidades públicas, sobre todo, porque estas tienen una representación singular para cada uno de nosotros:

El conjunto de las relaciones entre los lugares, por el modo como los conocemos (o los imaginamos) y por cómo los valoramos, constituye en la mente de cada uno de nosotros una especie de mapa del mundo. Cada sujeto es, en efecto, portador de un mapa mental del mundo que le permite orientarse en las relaciones con los lugares y con los otros sujetos $y$, a través de las representaciones, estar mentalmente en relación con otros lugares y sujetos distantes (Signorelli, 2012, p. 184).

Lo interesante de la puesta en escena de los conceptos de antropología urbana esgrimidos por Signorellli, se encuentra en la configuración de un objeto de estudio particular que resulta de la relación entre los sujetos y los lugares. La autora considera que: "Los sujetos humanos, colectivos o individuales son siempre sujetos localizados; complementariamente, los lugares de la vida humana son lugares subjetivados. Io que equivale a decir que no existen seres humanos que no estén en algún lugar, y no existe ningún lugar que no esté humanizado, aunque sea solo por haber sido pensado por seres humanos" (Signorelli, 2012, p. 175). Esta relación intrínseca entre el ser humano y el espacio es la esencia de toda investigación de tipo urbano. De la misma forma, es la pauta para la generación de nuevos marcos metodológicos que buscan ver integralmente y de manera holística, dicha relación. Entender el espacio como un elemento humanizado es darle sentido a lo relacional. En otras palabras, el sentido del lugar, la esencia de los espacios, depende en gran medida de las cualidades y las características de quienes habitan en ellos. Esta relación se puede ver a la inversa si planteamos, en referencia a lo propuesto por Aguilar y Signorelli, que los sujetos están constituidos en cierta medida, por las condiciones del espacio o, si se quiere, del contexto donde habitan. Es una relación intrínseca, simbiótica.

\section{Geografía, urbanismo y arquitectura: líneas tangenciales con el espacio público}

Dentro de este ejercicio no se podían obviar aquellas disciplinas que han contribuido a que el espacio público sea estudiado como un objeto, a veces desligado de las interacciones que le dan forma y sentido, pero que han demostrado también un importante esfuerzo en revertir posturas y arrojado la posibilidad de formular nuevas preguntas de investigación. Algunas nociones sobre el espacio público que emergen de la geografía, el urbanismo y la arquitectura han desafiado sus lindes, tendiendo lazos hacia la subjetividad y cimentando bases frescas en las que aparecen categorías de análisis más asociadas con las humanidades que con las ciencias duras, en estos casos, situados desde la geografía cultural y la sensibilidad hacia los paisajes ordinarios (Claval, 2007; Tuan, 1976). Por otra parte, la arquitectura y el urbanismo son expuestos aquí bajo la amalgama de lo urbano-arquitectónico. Se retoman algunas lecturas clásicas, pero también tienen cabida en este diálogo posiciones más recientes (Carr, 1995; Frick, 2011; Lynch, 1998; Norberg-Schulz, 1980).

Por su parte, Borja y Muxi (2003, p. 27) reconocen que el espacio público es un concepto multidimensional, destacando por ejemplo que desde un enfoque jurídico "es un espacio sometido a una regulación específica por parte de la administración pública, propietaria o que posee la facultad del dominio sobre el suelo que garantiza la accesibilidad a todos y fija las condiciones de utilización y de instalación de actividades", pero señalan también que, desde una dimensión sociocultural, "es un lugar de relación y de identificación, de contacto entre las personas, de animación urbana, y a veces de expresión comunitaria". Así, se reconoce que, aunque en este texto se incluye la geografía, el urbanismo y la arquitectura para revisar qué es 
ahora el espacio público, no solo se procura un recorrido a través de diversas disciplinas, repasando qué se dice desde un campo en contraposición a otro, sino que se invita a una reformulación del concepto o, posiblemente, a múltiples reformulaciones.

Recuperando la aportación de Paul Claval, podemos afirmar que el espacio público se convierte en lugar al momento en que este es reconocido por quienes lo habitan y, a su vez, permite que se orienten. Es decir, cuando son memorizadas algunas imágenes concretas de un espacio público determinado (reconocimiento) y al situar los espacios y sus elementos (orientación). Aunque esto no es suficiente, siempre resulta necesario nombrarlos (cualificarlos) para hacer compartido este ejercicio de orientación y reconocimiento. Así, partimos con una primera aportación derivada de la geografía humana: "Un descubridor quiere conservar la memoria de las tierras que descubrió y hacer que todos las conozcan; para hablar de lugares y ambientes, no hay otro medio que proceder al bautizo de la tierra y elaborar un vocabulario propio para calificar los diferentes aspectos del espacio" (Claval, 2007, p. 201). Esto sucede cuando los espacios públicos son nombrados, reconocidos y resemantizados por grupos de sujetos. El hecho de distinguir un sitio por un nombre común posiblemente le abone algo a su condición de público. Aquel nombre es, de cierta forma, de todos.

Por su parte, Yi-Fu Tuan (1971) explica que el paisaje obedece a un ordenamiento de la realidad desde diferentes ángulos: uno vertical, el cual ve al paisaje como dominio y otro horizontal, que permite apreciar cómo la gente actúa; la primera perspectiva alude a lo objetivo, mientras que la otra es una mirada subjetiva. La combinación de ambas visiones, afirma Tuan, solo es posible a través del ojo de la mente. Este autor sugiere el cruce de miradas como una herramienta práctica para emprender un análisis interpretativo de los paisajes ordinarios: aquella mirada objetiva, misma que podría asociarse con la de la planificación territorial, necesita nutrirse de aquello que aportan los sentidos cuando se es partícipe de las interacciones, y que podría asociarse con el usuario. “(...) podemos aprender a ver no solo qué tan complejas y variadas son las formas de vida humana, sino también qué tan difícil es lograr cualquier hábitat acorde con todo el potencial de nuestro ser" (Tuan, 1976, p. 101). Por ello, si leemos el espacio público como paisaje ordinario, seguramente encontraríamos en él un detonador de los sueños y del imaginario colectivo de quienes lo habitan. Para la geografía urbana contemporánea resulta relevante incorporar la perspectiva cultural que, además de incidir sobre lecturas complejas del espacio público, repercuta asertivamente sobre los modos de asignarlos, proyectarlos y edificarlos.

Otra aportación ineludible es la que se encuentra en la geografía urbana posmoderna, ampliamente estudiada por Soja (2000). Abordando casos como la posmetrópolis de Los Ángeles, el autor revisa críticamente la dicotomización público/privado del espacio. El espacio público no pierde sus atributos al momento en que determinadas prácticas lo reforman, tornándolo en apariencia un ámbito privatizado. Estos entornos pueden ser entendidos como de la esfera pública pues, aunque el urbanismo obsesionado con la seguridad y la arquitectura de la fortificación pondrían en duda el acceso libre a ciertos lugares dotados por el Estado, en ellos se seguirán manifestando confrontaciones de otra naturaleza, como conflictos de etnicidad, raza o género. Así, de acuerdo a Soja, habría que hacer a un lado la noción universalista y homogeneizante de que el espacio público es escenario exclusivo de las diferencias de clase. La hegemonía y contrahegemonía que se ejerce sobre el espacio no se ciñe al factor económico: son entonces componentes sociales y culturales los que codifican también las nuevas modalidades en que se nos presenta en plazas cívicas, corredores urbanos, parques barriales, atrios e, incluso, vestíbulos de centros comerciales.

Otros estudiosos con enfoques similares al de este geógrafo norteamericano, tales como Crawford (2004), Davis (2004) y Sorkin (2004), coinciden en comprender al espacio público de 
nuestros días como un parque temático. Señalan tres condiciones para considerar a este como un concepto que atraviesa por una intensa crisis. La primera tiene que ver con la disipación de las relaciones de estabilidad geográfica, tanto cultural como físicamente hablando, incidiendo sobre categorías como la identidad local; la segunda se relaciona con el incremento perturbador de la seguridad, incidiendo en nuevas formas de manipulación e impulsando situaciones - aparentemente irreversibles- de segregación; por último, el espacio público como alusión del parque temático trae consigo la simulación y el hiperconsumo como características clave, impactando no solo sobre las prácticas en el espacio compartido, sino sobre las representaciones que los sujetos construyen, reconstruyen y recrean en torno a él.

El abordaje que plantea la visión urbano-arquitectónica hace referencia, en general, al espacio público visto desde una perspectiva que lo considera parte del territorio. La óptica que se utiliza para esto apuesta, muchas veces, por el estudio de la forma de la ciudad, el análisis de la imagen urbana, las problemáticas vinculadas con coberturas de infraestructura y equipamiento y demás aspectos relacionados con el espacio y su configuración morfológica. El concepto de espacio (o de lugar) desde estas disciplinas, surge de los enunciados de la teoría de la arquitectura, particularmente la de los años 60 y 7', momento de crisis para el Movimiento Moderno. Autores como Christian Norberg-Schulz y Kevin Lynch le confieren una posición trascendental al concepto del lugar.

En su libro Genius Loci, Norberg-Schulz, recuperando el pensamiento de Martin Heidegger, Sigfried Giedion, entre otros y, explorando las teorías de la Gestalt, aborda con cierta profundidad los conceptos de espacio y lugar: "¿Qué queremos decir con la palabra lugar? Obviamente queremos referirnos a algo más que una localización abstracta. Nos referimos a una totalidad hecha de cosas concretas que tiene sustancia material, forma, textura y color. Estas cosas juntas determinan un carácter ambiental, el cual es la esencia del lugar" (NorbergSchulz, 1980, p. 6-8). Este autor, a su vez, reconoce que el manejo del término espacio, no es nuevo para la teoría de la arquitectura, pero que su uso nos puede conducir a muchos significados. Por eso se hace necesario hablar del concepto de espacio habitable y así, evitar confundirlo con el espacio abstracto propio de la geometría tridimensional. Aun así, hablar de espacio habitable resultaría poco satisfactorio, tendríamos que hablar - de acuerdo a NorbergSchulz- de espacio concreto y así evitar caer en la idea de un espacio homogéneo e isotrópico. El concepto de genius loci, también ha sido usado por Aldo Rossi para denotar el espíritu del lugar (Rossi, 2015). Debe entenderse este espíritu como la esencia misma del contexto espacial, lo que le otorga una singularidad o características particulares, que lo hacen diferente de otros, y a la vez, reconocible ante los demás.

Por su parte, para Kevin Lynch el estudio de lo urbano, incluido el espacio público, está fundamentado en la posible imagen de la ciudad, característica producida por los elementos que la configuran en sus aspectos físicos y espaciales, y que a la vez son producidos socialmente. Para el autor, en la ciudad, imagen y realidad se manifiestan de diversas formas, pero ambas configuran los elementos primordiales para reconocer lo urbano: "Si bien la vida dista mucho de ser imposible en el caos visual de la ciudad de hoy, la misma acción cotidiana podría asumir un nuevo significado si se le ejecutara en un marco más vívido. Potencialmente, la ciudad es en sí misma el símbolo poderoso de una sociedad compleja. Si se la plantea bien visualmente, puede tener asimismo un intenso significado expresivo" (Lynch, 1998, pp. 13-14). En este sentido, los habitantes de la ciudad tendrán siempre como referente básico de su vida cotidiana los espacios conocidos, los espacios vividos por su propia experiencia; los mismos que ellos construyen con su acción y que de forma recíproca, condicionan su actuar. Los espacios urbanos entonces estarán determinados por su uso, por sus funciones e incluso por su contenido estético. El papel de la vida cotidiana aquí aparece como factor fundamental para la 
concreción de los espacios urbanos y, el espacio público en específico, es a la vez escenario para las interacciones de los habitantes de la ciudad, es un actor urbano.

Dentro de las posturas más actuales sobre el concepto del espacio público desde las disciplinas relacionadas con lo urbano, se pueden encontrar virajes teóricos y metodológicos que se inclinan por la visión interdisciplinaria. Algunas posturas incluso ponen en un mismo nivel de análisis y de importancia al espacio público y a lo social: “(...) el componente central de la organización constructivo espacial de la ciudad y al mismo tiempo el vínculo más importante junto con su organización social" (Frick, 2011, p. 67). A pesar de que su teoría está más cercana a las condiciones técnicas que debe poseer lo urbano y los elementos que hacen parte de su estructura, Frick afirma sin aspavientos que: "Lo esencial en cuanto al espacio público es lo que sucede en él: la acción y el comportamiento de los habitantes y transeúntes (...) La atención por parte de los usuarios y los observadores está dirigida en primera instancia al espacio social, muy concretamente a las personas que se mueven en la ciudad" (Frick, 2011, pp. 67-68). En segundo nivel, el autor considera los aspectos constructivos de carácter físico espacial, pero reconoce que ambos elementos forman parte de la percepción y subjetivación de la imagen de la ciudad, siendo esto en última instancia, una forma de construcción del espacio público. El interés de relacionar los componentes construidos de la ciudad con sus artífices denota la importancia que posee la acción de los habitantes, de los sujetos, en la constitución del espacio público, dado que estos determinan los acontecimientos que suceden en los escenarios urbanos, en otras palabras, construyen desde su vivir cotidiano este elemento estructural de la ciudad.

En esta superposición conceptual, en donde la interdisciplinariedad juega un papel importante, podemos observar que la relación espacio público y sociedad es de carácter complementario. A raíz de esto Carr afirma que: “algunas veces el espacio público no refleja adecuadamente la necesidad de los usuarios y como resultado, se dan fallas en el diseño y el manejo de los mismos" (Carr et al, 1995:1). Es necesario anotar que dicha relación puede generar aportes positivos o negativos a la constitución de lo público como concepto y como elemento urbano, lo mismo puede pasar para los sujetos y grupos sociales que pueden verse afectados en su desarrollo por condiciones externas a ellos mismos, muchas veces referidas a situaciones y características del espacio. Si bien la obra desarrollada por Carr (y sus coautores) es una revisión de las condiciones en las que se ha dado el desarrollo del espacio público de las ciudades norteamericanas, muchos de los postulados esgrimidos pueden relacionarse con el estado de este concepto en otras latitudes. Como hecho fundamental, estipulan una trilogía de valores preponderantes: los espacios públicos deben ser sensibles, democráticos y significativos (Carr, Francis, Rivlin \& Stone, 1995, pp. 19-20).

En concordancia con el planteamiento de Carr y colaboradores, la obra de Gehl (2006) combina una concepción del espacio público como hecho físico y como hecho construido socialmente a partir de las relaciones de los sujetos. Es fundamental entender en su obra la importancia de las actividades espaciales de los sujetos, mismas que configuran las formas de uso y la intensidad del mismo. Este autor considera que la relevancia del espacio público determina las cualidades urbanas de las ciudades, valorando el concepto del espacio público como un hecho fundamental para la humanización de la ciudad, y juzgando duramente los fenómenos que van en contravía física y social, de la posibilidad de cohabitar el hábitat urbano enarmonía.

\section{Reflexiones finales}

Como se ha argumentado a lo largo de este texto, la sociología y la antropología han sumado a su visión y a su objeto de estudio una idea de espacio que es complementaria a sus necesidades. Y viceversa, las disciplinas que tenían como fundamento el espacio, el lugar o el 
territorio (geografía, urbanismo y arquitectura), han empezado a mostrar interés por el sujeto y los grupos sociales. La relación entre ambos elementos es inherente: sujeto y espacio (o sociedad y espacio, si se quiere) están imbricados en una red que superpone problemáticas y situaciones que complejizan la comprensión de lo urbano, unificando y definiendo temáticas afines a diversas disciplinas.

De la misma manera, la dialéctica entre lo público y lo privado dista de ser hoy una manifestación de la ruptura estática entre uno y otro concepto. Por el contrario, se puede establecer que la dicotomía público/privado ha dejado de ser una relación de ruptura (como se ha considerado tradicionalmente), para convertirse en una relación dialógica. De otra forma, se puede decir que hay una complementariedad entre ambos elementos (desde una perspectiva conceptual y física), situación que les da dinamismo y complejidad al mismo tiempo. En este sentido, los límites existentes entre lo público y lo privado actualmente se están desdibujando. Ambos son escenarios de disputas y negociaciones que generan una nueva forma de comprender lo urbano. A pesar de que algunas veces se privilegien las acciones que se celebran en el espacio, y que otras veces se les dé mayor importancia a las formas (el aspecto físico) que lo representan, la importancia de buscar la comprensión de lo urbano (en particular lo que se refiere a la relación de los dos conceptos en mención) desde una perspectiva interdisciplinar, es fundamental para el desarrollo de los estudios de la ciudad en nuestros días.

Esta pretensión por deconstruir el concepto de espacio público, entendida básicamente como una forma de diferenciación, no necesariamente lingüística, pero sí conceptual/disciplinar, es una estrategia para comprender el concepto de espacio público como un elemento transversal a otras formas de espacio (entre ellas el espacio urbano, el espacio abstracto, el espacio social). De igual manera, permite ubicar dicho concepto en distintas escalas de interpretación territorial que van de lo general a lo particular (o desde lo regional a lo barrial), denotando su importancia en la configuración de los distintos sistemas urbanos y sociales. Si bien han quedado exentos de este texto algunos otros de los postulados que se pueden encontrar sobre el concepto del espacio público, consideramos que, con este trabajo, los lectores pueden tener una idea clara de varios de los puntos críticos y de reflexión que son actualmente parte de la discusión teórica sobre este concepto. Intentamos así, sumar a la crítica constructiva de un concepto presente en nuestra cotidianidad urbana.

\section{Referencias}

Aguilar, M. (2012). Antropología urbana y lugar, recorridos conceptuales. En A. Giglia y A. Signorelli (Coords.), Nuevas topografías de la cultura (pp. 113-144). México DF: Universidad Autónoma Metropolitana.

Borja, J. (2007). La ciudad conquistada. Alianza. Madrid.

Borja, J. y Muxi. Z. (2003). El espacio público: ciudad y ciudadanía. Barcelona: Electa.

Carr, S., Francis, M., Rivlin, L., \& Stone, A. (1995). Public space. Cambridge: Cambridge University Press.

Castells, M. (1976). La cuestión urbana. México: Siglo XXI.

Claval, P. (2007). A geografía cultural (3ª edición). Florianópolis: Editora da UFSC.

Crawford, M. (2004). El mundo en un centro comercial. En M. Sorkin (Ed.), Variaciones sobre un parquet temático: la nueva ciudad americana y el fin del espacio público. Barcelona: Gustavo Gili. 
Davis, M. (2004). Fuerte Los Ángeles: la militarización del espacio urbano. En M. Sorkin (Ed.), Variaciones sobre un parque temático: la nueva ciudad americana y el fin del espacio público. Barcelona: Gustavo Gili.

Delgado, M. (1999). El animal público: hacia una antropología de los espacios urbanos. Barcelona: Anagrama.

Delgado, M. (2011). El espacio público como ideología. Madrid: Los Libros de la Catarata.

Derrida, J. (1989). La escritura y la diferencia. España: Anthropos.

Duhau, E. y Giglia, A. (2008). Las reglas del desorden: habitar la metrópoli. México: Siglo XXI Editores, Universidad Autónoma Metropolitana.

Frick, D. (2011). Una teoría del urbanismo: acerca de la organización constructivo-espacial de ciudad. Bogotá: Editorial Universidad del Rosario.

Gehl, J. (2006). La humanización del espacio urbano. Barcelona. Editorial Reverté S.A.

Harvey, D. (1977). Urbanismo y desigualdad social (3a edición). España: Siglo XXI Editores.

Lefebvre, H. (1991). The production of space. London: Blackwell.

Lynch, K. (1998). La imagen de la ciudad. Barcelona: Gustavo Gili.

Madanipour, A. (2003). Public and private spaces of the city. London: Rothledge.

Norberg-Schulz, C. (1980). Genius loci: Towards a phenomenology of architecture. New York: Rizzoli.

Powell, J. y Howell, V. (2004). Derrida para principiantes. Argentina: Era Naciente SRL.

Rossi, A. (2015). La arquitectura de la ciudad. España: Gustavo Gili.

Signorelli, A. (2012). Sujetos y lugares. La construcción interdisciplinaria de un objeto de investigación. En A. Giglia y A. Signorelli (Coords.), Nuevas topografías de la cultura (pp. 175198). México: Universidad Autónoma Metropolitana.

Soja, E. (2000). Postmetropolis: Critical studies of cities and regions. Los Angeles: Blackwell Publishing.

Sorkin, M. (2004). Nos vemos en Disneylandia. En M. Sorkin (Ed.), Variaciones sobre un parquet temático: la nueva ciudad americana y el fin del espacio público. Barcelona: Gustavo Gili.

Sorkin, M. (2004). Introducción: variaciones sobre un parque temático. En M. Sorkin (Ed.), Variaciones sobre un parque temático: la nueva ciudad americana y el fin del espacio público. Barcelona: Gustavo Gili.

Tuan, Yi-Fu. (1976). Thought and landscape: The eye and the mind's eye. En D. Meinig (Ed.), The interpretation of ordinary landscapes: Geographical essays (pp. 89-102). Oxford: Oxford University Press.

Zukin, S. (1993). Landscapes of power: From Detroit to Disney World. Berkeley: University of California Press. 